\title{
National systems of innovation, innovation niches, and diversity in university systems
}

\section{S. Datta, M. Saad, D. Sarpong}

\section{Introduction}

Universities are increasingly being recognised as institutional actors that play a central role in developing the innovative capacity of the societies in which they are embedded (Etzkowitz and Leydesdorff, 2000; Mowery and Sampat, 2005; Saad et al, 2014). In recent years scholars and policy makers alike have focused their attention on the diverse roles that universities perform in the innovation processes (Mowery and Sampat, 2005; Freeman, 1995). Universities are seen as agents that both directly and indirectly contribute to such processes and consequently help in promoting regional and national economic growth (Valero and Van Reenen, 2018; Guena and Muscio, 2009; Edquist, 2005). In spite of this recent focus on the role of university in innovation systems, considerable gaps remain in our understanding of the contribution of academia to the innovation process. Theories of innovation that adopt a systems perspective have highlighted the centrality of the university sector as a key institutional actor in national innovation system (Hicks, 2012; Etzkowitz and Leydesdorff 2000; Nelson, 1993; Freeman, 1995). However, the sector is conceptualised in a largely homogeneous way within these frameworks. More specifically, there is an implicit preference for a 'one-size-fits-all' model of the university system in these frameworks. The empirical reality is, however, quite different. There is still considerable diversity in university systems, particularly in developed countries. In the extant literature on higher education systems (HES), diversity is often viewed as a positive and necessary feature (Gurin et. al., 2002; Trow 1997). Diversity, it is argued, can significantly help to improve the performance of higher education systems, particularly when active interaction within the system is envisaged (Eastman and Santoro, 2003; Conceição and Heitor 2005; Horta et al., 2008; Saad et al., 2014). The importance of diversity as an engine for economic growth was also highlighted by Nelson and Winter (1982) and Audretsch et al. (2004). In this paper we develop a conceptual framework within which this heterogeneity can be understood and then offer examples of such diversity within the UK higher education sector.

The paper is structured as follows: first, existing theoretical constructs that have looked at the role of universities in innovation processes are examined and critically evaluated. Second, in order to understand the extent of diversity within the sector, a knowledge-based framework is developed to identify the available innovation niches within which the university sector can specialise. When universities specialise in providing innovation inputs of similar kinds, different strategic clusters within the sector emerge (Cook and Huggins, 2018). These groups form the basis of diversity in academia in relation to the innovation activities that 
universities pursue. It is the argument of this paper that existing theories are particularly deficient in accounting for this diversity. Third, several examples from the UK university system are presented, with the dual objectives of identifying various strategic clusters that exist within the higher education sector and explaining their contribution to the national innovation system. The paper concludes with some critical reflections on the pros and cons of having distinct strategic clusters within the higher education sector.

\section{Conceptualising the Role of Universities in the Innovation Ecosystem of a Nation}

The role of academia has been accorded importance in the innovation literature which adopts a systems perspective. In contrast to theories that project the individual entrepreneur as the primary engine for innovation, systems-oriented theories highlight the importance of institutions and institutional actors in the genesis of new products, processes and services. Three such frameworks - the National System of Innovation, the Triple Helix System and National Innovative Capacity - are considered here, in order to develop an understanding of the diverse contributions of universities to the innovation process. These theories have distinct perspectives on the role and purpose of academia in the innovation ecosystem at the national and regional levels (Carayannis et al., 2018a).

\section{The National System of Innovation}

According to the network perspective of the National System of Innovation (hereafter NSI), a firm's ability to innovate is dependent on a host of interlinked and interdependent factors, such as the quality of the national education system, industrial relations, quality of technical and scientific organisations, government policies and cultural traditions (Acs et al., 2017; Martin, 2003; Freeman 2002). NSI prescribes a broad division of labour for actors involved in the innovation process. It is the role of firms to convert ideas and inventions to innovation. Government plays a supporting role by formulating appropriate industry and technology policies and providing funds for research. The higher education sector plays a critical role in educating and training people (Saad et al., 2014) as well as performing research that adds to the generation of new ideas in the economy (Kwon and Motohashi 2017; Edquist, 2005). Whilst the importance of the role of academia in the NSI is well acknowledged, the scope for the commercialisation of research output is limited (Freeman, 1995; Nelson, 1993; Lundvall, 1992). As Mowery and Sampat (2005) point out, the way the role of university is conceptualised in NSI makes it open to the charge that it subscribes to a 'linear model' of innovation where ideas and prototypes are formed in research laboratories by scientists and inventors, which are then taken up by others who proceed to commercialise them. NSI theorists 
(Nelson, 1993; Freeman, 1995) have acknowledged the influence of Vannevar Bush who developed in 1945 the 'blueprint' for the post war United States Research and Development (R\&D) system through his publication 'Science: The Endless Frontier', which highlighted the role of universities in bringing forward a continuous stream of new ideas to the marketplace. He saw this as the principal means of retaining the technological edge of the US over other nations. The 'linear model' has been the subject of influential debates by scholars, some of whom have argued that the innovation process rarely follows this pattern (AmankwahAmoah, 2016; Kline and Rosenberg, 1985). Rosenberg (1994), in particular, has forcefully argued for the serendipitous nature of invention and innovation, where the inventor often is not aware of how the invention will ultimately be commercialised and used. Notwithstanding such critiques, NSI and the role of universities within it has gained wide acceptance both amongst scholars and policy makers in recent times.

\section{The Triple Helix System}

The Triple Helix System (hereafter THS) came as a reaction to NSI and, in particular, to the division of labour specified in it. Etzkowitz and Leydesdorff (2000) argue that the development of innovation capability at national and regional levels is contingent on the extent of information and knowledge exchange between government, industry and academia. Triple helix innovation occurs when the roles of the three institutional spheres overlap with each other. Embedded in this theory is the idea that the circulation of people within the three spheres helps learning and thus contributes to the innovative capacity of the economy (Ivanova and Leydesdorff, 2014; Etzkowitz and Dzisah, 2008). There are similarities between the NSI and the THS. Both frameworks take an institutional perspective to explain innovation dynamics and to acknowledge the three principal institutional spheres within the system, corresponding to government, industry and university, as key players. But there are important differences between the NSI and THS, especially regarding the role of the university and its relationship with other actors within the system. This particular difference is discussed later in this section.

THS is more normative than NSI, in the sense that it prescribes one preferred model of university-industry-government (U-I-G) linkages (Wu et al., 2017; Phillips, 2014). THS, according to Etzkowitz and Leydesdorff (2000), portrays the innovation system via the framework of an evolutionary process involving three stages of network development. First, it is possible that in a given society, university and industry are overwhelmingly put under 
government control, thus giving rise to a 'Statist' model where there is little manoeuvrability for academia and industry, as both would be highly regulated. The second stage in the evolutionary process is reflected by the so-called 'laissez-faire' model of relationship between institutional actors (namely government, industry and academia), each with clearly delimited boundaries, so that while they interact they readily allow knowledge circulation within the network. This 'division of labour' among institutional players has the effect of limiting the scope of synergy that would be expected of co-operative ventures. The third stage of evolution in the THS, where there are overlaps between the roles of the three institutional actors, is where the system achieves the culture best suited for innovation to occur. Within this stage universities become entrepreneurial, hybrid organisations evolve and industry gets more involved in supporting higher education and training, while policy becomes increasingly proactive with respect to innovation projects and the development of knowledge networks.

In its most highly evolved form, THS is explicit in its advocacy of the entrepreneurial university (Etzkowitz et al, 2000). The entrepreneurial university is one in which the third mission' of the university - i.e. its engagement with industry and the wider community - takes precedence over its traditional missions of teaching and research (Shane, 2004). Universities would thus be expected to be at the forefront of innovative activities, undertaking industryoriented research and development and actively commercialising their research output. The Bayh-Dole Act of 1980 in United States, which gave US universities control of their invention and other intellectual properties, is considered by THS scholars as a watershed in university entrepreneurship. Such regulatory action is considered necessary in providing the incentive to universities for engagement in entrepreneurial activities. The experiences of US universities, such as MIT, Stanford and University of California, Berkeley, suggest that US universities have become more entrepreneurial after the enactment of the Bayh-Dole Act, leading to more patenting, licensing and spin-off activities. Such activities are seen to be a measure of universities' increased innovative capacity and the development of the Triple Helix relationships as an innovation system.

Despite their individual distinctiveness, there is lot in common between NSI and THS; one deepens and enriches understanding of the other. Both emphasise the importance of national actors, such as government and industry and focus on the nature of interactions between them. The main distinction drawn between NSI and THS is in their attribution of the lead role in the innovation process, which is to firms (production sphere) in the NSI and to universities (knowledge sphere) in THS. 


\section{National Innovative Capacity}

National Innovation Capacity (hereafter NIC) is a framework based on a synthesis of three distinct theoretical concepts. These are the 'Endogenous Growth' theory (Romer, 1990; Nelson and Romer, 1996), the concept of NSI (Freeman, 1995; Nelson, 1993; Lundvall, 1992) and Cluster-Based Theory (Cook and Huggins, 2018; Porter, 1998). The framework attempts to specify the determinants affecting the innovation process, which in turn results in innovation output to varying degrees across different countries (Furman et al, 2002). NIC is seen as a country's potential to produce commercially relevant innovations and this, in turn, is dependent on a variety of factors, including human capital and financial resources available for R\&D activity, level of technology sophistication, intellectual property protection and related and supporting industries (Furman et al, 2002). The Endogenous Growth theory (Romer, 1990) explicitly links the stock and quality of the human capital of a country to the level of technological sophistication it possesses and consequently to the rate at which its economy grows (Danquah and Amankwah-Amoah, 2017). Technological changes are endogenous to the model, as they arise from the process of normal business operations, including R\&D activities and up-skilling the labour force, which allows them to be more productive and creative. NIC builds on NSI, so there are common elements between the two theories: both frameworks stress the importance of R\&D and the necessity of supportive institutional structures that include protection of intellectual property rights. However, NIC considers these necessary but not sufficient conditions for the development of innovation capability at national level.

The other key element in NIC is the notion of 'clusters'. Porter and Stern (2002) incorporate the cluster idea into NIC to bring to the forefront the role of competition, which they consider central to the innovation process. Clusters, being the geographical concentration of interconnected companies and institutions in a particular field, ensure the availability of high quality specialised inputs and create "a context that encourages investment coupled with intense local rivalry, pressure and insight gleaned from sophisticated local demand, and the local presence of related and supporting industries" (Porter and Stern 2002: 6). Their argument is that developing this kind of environment is crucial for improving the innovative capacity of nations. The most well-known example of a cluster in the US is the Silicon Valley, progenitor of many high technology companies, some of which have grown into multi-billion dollar enterprises. The success of Silicon Valley has been attributed to its network of institutions (including excellent universities such as Stanford 
University), strong protection and enforcement of intellectual property rights, availability of risk tolerant venture capital and angel funding, a culture of entrepreneurship and skilled workers' strong social networks. NIC advocates argue that the Silicon Valley model should be replicated to promote the innovative capacity of other regions and nations. However, the appeal of this argument runs the risk of giving credence - particularly in developing countries - to technology policies that are politically-driven and top-down orientated, inappropriate to the long-term development objectives of these countries (Malairaja, 2003; Saad et al, 2008, Datta and Saad, 2011).

NIC highlights the importance of skilled labour that is capable of carrying out R\&D activities. It explicitly mentions investment in education and training as one of the key determinants of the innovative capacity of a nation (Furman, Porter, \& Stern, 2002; Romer, 1994; Saad et al, 2014). In this respect it is similar to NSI but there is a distinction in the emphasis that is put on R\&D in the two approaches. In NSI, universities appear as institutions that not only produce a skilled workforce but also generate original ideas and inventions that are ultimately commercialised by private firms (Edquist, 2005). In contrast NIC, while acknowledging the importance of the university sector for its contribution to the development of human capital, underplays its direct role in the innovation process. The production of appropriate human capital appears an important source of national competitive advantage (Coleman, 1988; Scott, 1998). This is echoed by Gimeno et al. (1997) and Pennings et al. (1998) who suggest that overall human capital is positively associated with economic performance.

NIC accords to business organisations the leading role in innovation of new products and services. Business firms invest in R\&D, driven by the fear of losing their market positions to competitors and in the knowledge that such investments would be protected through intellectual property rights. The role of universities in this scheme is an indirect one: it trains the scientists and engineers who ultimately work in the R\&D laboratories of business organisations; it is otherwise a largely passive entity in the innovation process (Wheatley, 2001).

\section{Mapping the patterns of $U-I-G$ linkages described in the three frameworks:}

The NSI, THS and NIC offer distinct explanations for innovation dynamics. Notwithstanding their uniqueness, the three frameworks also cover some common ground. Table 1 shows both the differences and the similarities amongst the three concepts. All the three frameworks acknowledge the importance of academia in the innovation system, albeit with key differences in the conceptualisation of its roles. NSI and THS find a direct role of academia in 
the innovation process, with the former looking at it as a co-generator of new ideas alongside industry and the latter advocating a more active role in commercialising the ideas it generates. NIC, on the other hand, envisages academia playing the indirect but key function of educating and training the labour force, especially the future scientists and engineers who, when employed in industry, will directly participate in the creativity and innovation process.

\begin{tabular}{|c|c|c|c|}
\hline & Academia & Government & Industry \\
\hline $\begin{array}{l}\text { National System of } \\
\text { Innovation }\end{array}$ & $\begin{array}{l}\text { 1. Conducts both basic and applied research } \\
\text { with emphasis on the former } \\
\text { 2. Educate and train students thus raising the } \\
\text { stock of human capital in the economy } \\
\text { 3. Direct role in innovation process by being } \\
\text { originator of new ideas and products through } \\
\text { research }\end{array}$ & $\begin{array}{l}\text { 1. Funds basic research carried out through academia } \\
\text { 2. Frames appropriate S\&T policies to create an innovation } \\
\text { infrastructure } \\
\text { 3. Design appropriate 'rules of the game' to facilitate } \\
\text { learning between academia and industry }\end{array}$ & $\begin{array}{l}\text { 1. Implement ideas that are generated in the } \\
\text { academia } \\
\text { 2. Engages in applied research through } \\
\text { formal R\&D } \\
\text { 3. Improves products and process through } \\
\text { innovation }\end{array}$ \\
\hline Triple Helix Model & $\begin{array}{l}\text { 1. Becomes more entrepreneurial by } \\
\text { developing greater links with its economic } \\
\text { and social environment } \\
\text { 2. Engages in patenting, licensing, business } \\
\text { incubating and university spin offs } \\
\text { 3. Assumes an active role in knowledge } \\
\text { creation, diffusion and commercialisation }\end{array}$ & $\begin{array}{l}\text { 1. Plays a facilitating role to promote entrepreneurial } \\
\text { activities of the academia (ex. Bayh Dole Act) } \\
\text { 2. Design appropriate policies to facilitate overlapping of } \\
\text { roles between university and industry and itself } \\
\text { 3. Create the condition for circulation of labour between } \\
\text { the three institutional spheres }\end{array}$ & $\begin{array}{l}\text { 1. Develop close relationships with the } \\
\text { academia in several fronts } \\
\text { 2. Increasingly take over sponsorship of } \\
\text { research conducted at the university } \\
\text { replacing government funding } \\
\text { 3. Get directly involved in education and } \\
\text { training of the workforce }\end{array}$ \\
\hline $\begin{array}{l}\text { National Innovative } \\
\text { Capacity }\end{array}$ & $\begin{array}{l}\text { 1. Educates and train the workforce thus } \\
\text { raising the stock of human capital } \\
\text { 2. Focuses on training scientist and engineers } \\
\text { as they form the core which ultimately } \\
\text { produce the flow of new ideas in the } \\
\text { economy }\end{array}$ & $\begin{array}{l}\text { 1. Creates appropriate incentive structure in the economy } \\
\text { that encourage generation and commercialisation of new } \\
\text { ideas (ex. IPR protection) } \\
\text { 2. Designs policies to develop a strong competitive } \\
\text { environment which includes 'clusters' } \\
\text { 3. Invests in higher education to ensure that the stock of } \\
\text { human capital in the society is maintained and enhanced }\end{array}$ & $\begin{array}{l}\text { 1. Acts as the primary engine for generation } \\
\text { and commercialisation of new ideas, } \\
\text { products and processes } \\
2 \text {. Undertakes the majority of forma R\&D } \\
\text { spurred on by competition and by the fear of } \\
\text { losing market share } \\
\text { 3. Contributes to cluster formation }\end{array}$ \\
\hline
\end{tabular}

\section{Towards a conceptual framework: University contributions to innovation processes}

Although NSI, THS, and NIC, all refer to academia in their respective schema, it is never their focal point. There is a need to develop a more nuanced understanding of the role of universities in innovation processes and this section seeks to do this. The 'knowledge sphere' encompassing the university sector is intrinsically involved with the production and diffusion of information and theory and it is because of these functions that it assumes such a central role in innovation systems (Sarpong et al., 2017; Hicks, 2012; Guena, 1999). The range of activities that universities can pursue mainly constitutes inputs to various innovation processes. As innovation is diffused in so many different ways it has always been difficult to measure; there is considerable debate in the literature as to what can be considered input and what constitutes innovation output (Greenhalgh and Rogers, 2010). Patents, for example, are sometimes considered as a form of innovation output but, by itself, a patent does not represent innovation: only after a product based on a patent is commercialised and accepted by users can it be considered a bona fide innovation. Similarly, spin-offs based on the intellectual property of universities are a means of bringing about new products and processes. They are thus important innovation facilitators but it would be misleading to consider them as innovations in their own right. Economists have thus attempted to measure both inputs and outputs to develop an understanding of the intensity of innovative activities within a society, with the latter being measured through a variety of parameters, including 
exports of high technology products as a share of total exports and sales of 'new to market' and 'new to firm' products as a percentage total turnover (Greenhalgh and Rogers, 2010). Knowledge circulates within and between institutional spheres in explicit and tacit forms (Nonaka and Takeuchi 1995, Foray 2004). Universities deal in both forms of knowledge. While textbooks and journals provide the codified forms of knowledge, there is also transfer of tacit knowledge through face-to-face exchanges between the teacher and the student.

However, the knowledge that is exchanged between the university and the society is more complex than the binary distinction of the explicit and the tacit. Gibbons et al. (1994) suggest that knowledge can be abstract and acontextual (Mode 1) or it can be practical as it relates to particular problems that are local and context-specific (Mode 2). The Mode 1 and Mode 2 distinction has often been used to advocate the case for a university, which is more 'useful' to the society. The suggestion has been that universities have focused on Mode 1 knowledge production to the detriment of Mode 2 and a rebalancing is necessary. Others have challenged this view to be ahistorical, whereas in reality universities have often shared close linkages with industry and society in general (Martin, 2003; Etzkowitz and Leydesdorff 2000). For example, the civic universities in Britain were mainly set up by enlightened industrialists; these institutions focused on producing knowledge with industrial applications alongside training manpower with the specific skill sets that the industry required (Sanderson 1972). Despite the criticism, the two modes of knowledge production remain valid as a form of classification. It may be the case that universities have always produced practical knowledge but it is also true that they also have generated abstract theories that do not have any immediate practical application (Grillitsch, et al., 2018; Saad et al., 2004).

The two different ways of classifying knowledge discussed above can be synthesised to produce a conceptual framework which captures the multifaceted contributions of the university system to innovation processes. The four possible knowledge combinations are: (a) explicit and theoretical, (b) explicit and practical, (c) tacit and theoretical and (d) tacit and practical. To explain the framework, consider a peer-reviewed journal article in pure mathematics: this innovation input is explicit and theoretical, a form of basic research that may not have an obvious immediate industrial application. On the other hand, some scientific research is conducted with a specific industrial use in mind and they will fall under the explicit and practical category. Innovation inputs such as consultancy, coaching and knowledge transfer partnerships are likely to have a higher degree of tacit knowledge and they are used in a context that is specific, local and practical. University education is the obvious platform where both tacit and theoretical knowledge are generated in abundance. The codified 
knowledge of books and journals is transmitted, assimilated and transmuted through face to face interactions between the faculty and the student. Such knowledge is also generated through conferences and the interactions of like-minded peers across different institutions. It is well established that there are complex interplays between explicit and tacit knowledge (Nonaka and Takeuchi, 1995; Foray, 2004; Spender, 1996) and indeed between the theoretical and the practical (Gibbons et al., 1994). Classifying different innovation inputs into these four categories is not straightforward as it depends on the subjective judgement of the individual or group undertaking the classification. Despite this difficulty it should not take much effort to determine the two knowledge attributes (explicit/tacit and theoretical/practical) that are preeminent in most innovation inputs.

\section{Methodological note}

We develop our contribution in the context of the UK where universities have tried and tested various innovation models, approaches, and initiatives in response to their ever- evolving innovation ecosystems (Readman et al, 2018; Vallance et al., 2018; Guerrero et al., 2015). Methodologically, we draw on selected statistical data on the innovation activities of the UK published by the Higher Education Statistical Agency (HESA) and the now defunct Higher Education Funding Council for England (HEFCE) to illustrate how national innovation systems, innovation niches, and diversity in university systems plays out in practice. We have sought to focus on the data sets that have relate universities activities that have the potential to contribute in a directly to the national innovation system. We supplemented this with additional data set from the Higher Education-Business Community Interaction (HE-BCI) Survey that focuses on the innovation activities of universities, and THE 2010-2011 quarterly statistical reports on UK Universities Knowledge Transfer Partnerships (KTPs), published by the UK Innovation Agency-Innovate UK.

\section{Overview of the innovation landscape: The University's perspective}

The combinations of the different forms of knowledge open up distinctive innovation niches for universities to exploit. Universities have a choice to pursue all of them, any one of them or specialise in a select few. As shown in Table 5, the list of innovation inputs within the diagram is not exhaustive but provided as an illustration. Forms of innovation inputs are constantly evolving and they are often specific to a particular nation or region. The purpose of the conceptual framework is twofold: first, it specifies the knowledge dimensions in which different innovation inputs may differ from each other and second, it provides the necessary conceptual material to develop the idea of 'strategic clusters' within the university system. 


\section{Strategic Clusters and Diversity in University Models in the UK}

Diversity within the university sector can be conceptualised in multiple ways. It can be thought of in terms of the degree of control exercised by the state in the governance of the university whether it is a public, private, or a public-private partnership enterprise. In the THS framework the role of the university in its relationship with industry and government features as laissez faire, statist and hybrid systems, although the preference is for the evolved hybrid variant, which features the underlying culture of the so-called 'entrepreneurial university' (Etzkowitz et al, 2000). NSI and NIC do not address the issue of diversity in university models but they restrict the scope of the university within the national innovation system to a few key roles, as specified in Table 1 and one can draw the implication that universities would need to evolve in a specific direction in order to perform these functions. From the point of view of governance structures, the UK university sector is largely homogeneous, with most being autonomous, self-governing institutions in which government exercises control as part financier of student teaching costs, part funder of research activities and through assuring the quality of its services. The government does not play any role in setting up the curricula of the universities and does not influence, in a direct sense, their decision-making processes. The university structure is set up in a way that allows the government to either increase or decrease its investment in the higher education sector in a flexible manner. One way to think about how the state influences the university sector in Britain is by imagining that they control valves through which money flows from the government to the university sector: depending on the policies of the government in power, the flow of funds through these valves can be turned up, turned down or switched off completely. For the universities, less money coming through these valves means more dependence on market forces for sustenance. For example, as is currently the case, the government can decide to subsidise less and less the cost of education which, in turn, means that universities have to charge higher tuition fees in accordance with the dictates of market forces. Similarly, the state can decide to decrease the funding of universities' research activities and this can lead to universities bidding for more competitive research grants and targeting contract research from industry.

It is not necessary, however, to conceptualise diversity only from the perspective of the governance structure. Organisational diversity can also be evaluated by directly looking at the activities of the organisations within a particular population (Greve and Teh, 2018; Dunn and Jones, 2010). Depending on the context, it is possible that individual organisations within a particular organisational field are broadly similar to each other in terms of culture, scope of activities and structure but they can also differ significantly from each other (DiMaggio and Powell, 1983). Organisational diversity can be discerned in contexts where there is little 
differentiation in the governance structure of individual units in a particular organisational field. So, in order to consider diversity in the university sector in relation tothe role universities play in innovation processes, it would be more appropriate to think in terms of 'strategic clusters' occupying different niches within the innovation landscape. The idea of 'strategic clusters' in the university sector, as conceptualised here, is loosely based on the idea of 'strategic groups' popularised by Porter (1979), who used the concept in the analysis of firms within a particular industry. According to Porter 'strategic groups' are clusters of firms that emerge in an industry as they pursue distinctive strategies, either by differentiating their product offerings and consequently commanding premium price in the market, or by achieving a cost leadership position by having a lower cost base than competitors, thus enabling them to retain higher profit margins. In other words, strategic groups are formed within a particular industry when clusters of firms pursue a strategy that is distinctly different across clusters but is similar within clusters. The idea of strategic groups has gained currency as it has been moderately successful in explaining the differences in performance between different clusters of firms within an industry (Short el al, 2007). However, it is often difficult to analytically isolate and assess the competitive advantage gains deriving from group membership, as other factors such as firms' own resources and capabilities and the industry structure can and do significantly influence the profitability of the firm. The idea of strategic groups is basically consistent with the idea of specialisation, which dates back to the work of Adam Smith on the sources of the wealth of nations. Cost leadership often involves process innovation that can bring down the cost of production, while differentiation can be achieved through product innovation. If two clusters of firms in an industry specialise - one in product innovation and the other in process innovation - two strategic groups will eventually emerge through their respective specialisms.

The innovation landscape for universities is very different from the competitive markets to which Porter applied his idea of 'strategic groups'. Competitive markets exchange mainly private goods which have high excludability due to property rights amongst other mechanisms and high rivalry (meaning that once a unit of a good is consumed, the same unit cannot be consumed by someone else). However, the innovation inputs in which universities specialise often have properties associated with public goods. For example, basic research produces new knowledge which is non-rivalrous in nature: everyone can benefit from the new knowledge without diminishing its availability in any way. University education has also public good properties, mainly due to positive externalities such as its contribution to the development of a 'civil society'. Other university services, such as consultancy, contract research and licensing, can be comfortably classified as private goods. Innovation inputs provided by universities are therefore an assortment of public and private goods, hence 11 
concepts that have been exclusively developed for the latter should be applied with caution to the former. For this reason, it makes less sense to identify 'strategic groups' in the university system by distinguishing them in terms of cost leadership and differentiation strategies. Rather, one can conceptualise different strategic clusters in the university system which may emerge when universities specialise in innovation inputs differing in terms of the knowledge attributes presented in the earlier section. In the next section, we present further evidence from the university sector in the UK.

\section{Illustrations from the UK university sector}

This section demonstrates the different innovation niches that are served by the university sector in the UK. The aim is to discern patterns within the university sector by asking the following questions: do individual universities in the UK target the entire innovation landscape, or do they limit their scope, focusing on select innovation niches? If the latter is the case, are there clusters of universities within the sector that specialise in the provision of the similar kinds of innovation activities? Tables 2 and 3 show snapshots of the top performing universities in different innovation inputs.

Table 2 unavailable

Table 3

Top performers in knowledge transfer partnerships.

\begin{tabular}{lll}
\hline 1 & London South Bank University & 38 \\
2 & Queen's University, Belfast & 35 \\
3 & University of Sheffield & 31 \\
4 & University of Wolverhampton & 27 \\
5 & University of Reading & 24 \\
6 & University of Leeds & 23 \\
7 & University of Ulster & 22 \\
8 & University of Brighton & 21 \\
9 & University of Strathclyde & 21 \\
10 & Gorseinon College & 19 \\
Top ten sub-total 261 & & \\
Total knowledge transfer partnerships 269 & \\
Top ten share of knowledge transfer 27\% & \\
\hline
\end{tabular}

An evaluation of the performance of British universities according to different innovation parameters reveals a couple of strategic clusters. In one of them (Strategic Cluster A, see Table 4), specialisation of universities covers areas of basic research, contract research, patents and spin-offs. There are clear inter-linkages between these innovation niches (Guena and Nesta 2006). Pioneering basic research and the intellectual properties (IP) resulting from 
this would draw industry to universities' doorsteps which will further lead to success in contract research from industry. Such IPs could also boost patenting rates and spin-off activities. The University of Oxford is an outstanding example of this group, occupying top positions in quality related public research funding, research grant and contract research, patents and in a number of spin-offs. Other universities which belong to this group are the University of Cambridge, University College London, Imperial College and King's College. There are other universities, of course, that do not feature in Table 2 and which would belong to this strategic group. This particular strategic group has emerged as a result of several universities committing their resources to engagement in innovation activities through knowledge production, leveraged by policy instruments including copyrights, patents, licensing and spin-offs. One can suggest that there is a higher degree of specialisation in the production of explicit knowledge that can be both theoretical and practical within this strategic cluster.

Table 4

University's innovation landscape.

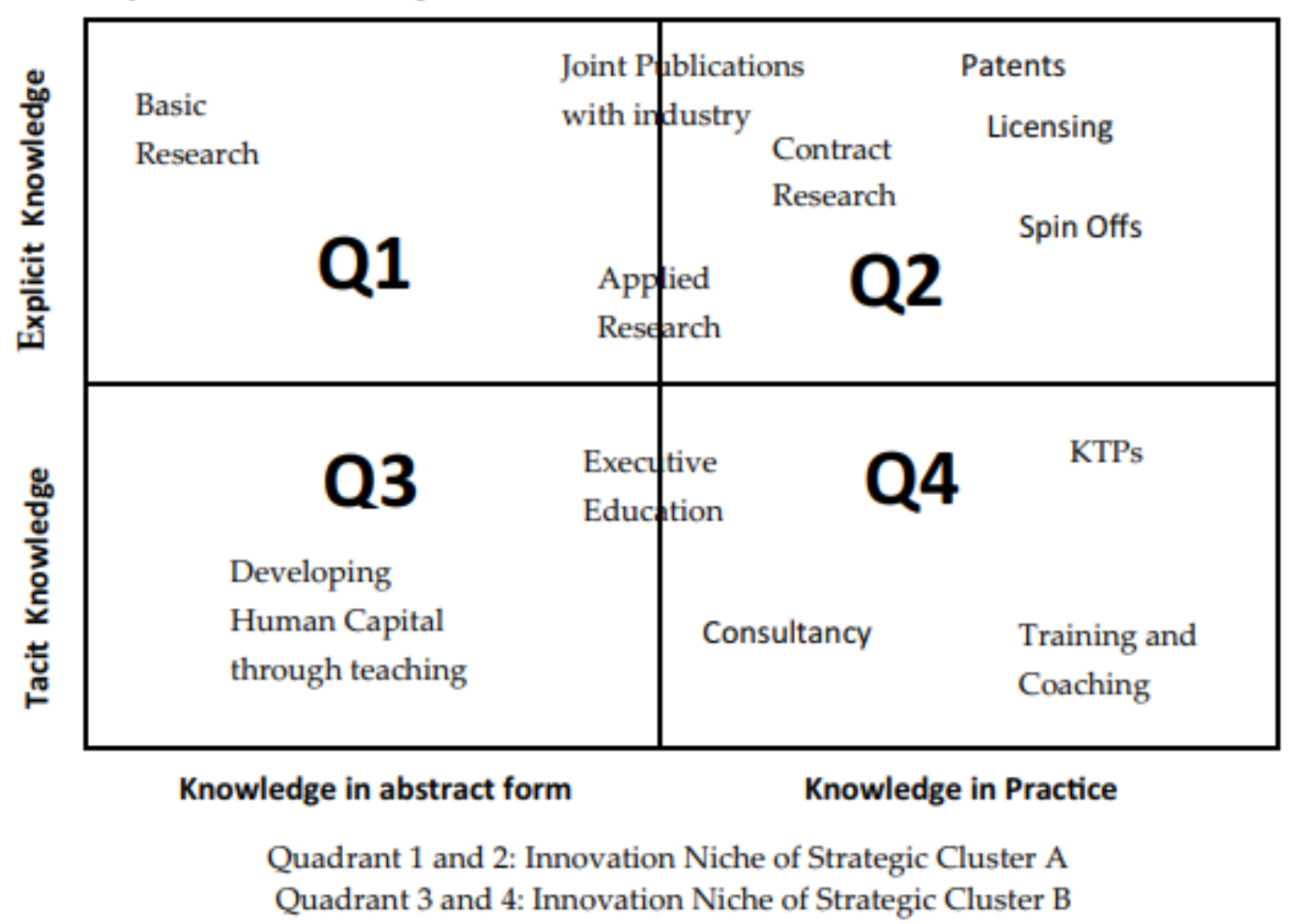

The second strategic cluster that can be identified is Strategic Cluster B, made up of quadrant 3 and 4 . In this strategic cluster, universities specialise in innovation activities having a direct impact on local regions, industry and community. Examples of such activities are Knowledge Transfer Partnerships (KTP), where academics work closely with KTP associates, people working on a full time basis within organisations and facilitating knowledge transfer from university to industry or communities and vice versa. Such processes require intangible 
and informal intellectual properties of academics and universities but need not involve formal IP (see Table 5 for a snapshot of the kind of knowledge transfer that happens through such partnerships). It is worth bearing in mind, however, that such relationships may also lead to codified, abstract knowledge, for example, through the publication of academic papers based on such experiences. Other innovation activities that would fall under this category are: contributions made under Consultancy, European Social Fund (ESF), Regional Development Authority (RDA) and European Regional Development Funding (ERDF). The university which immediately stands out in this strategic cluster is the University of Wolverhampton, which is in the top ten for KTP, Consultancy, ESF and ERDF. Other universities seeming to specialise on similar lines include the University of Hertfordshire and Coventry University.

Table 5

Knowledge transfer in KTPs.

\begin{tabular}{lll}
\hline University & Industry partner & Particulars of knowledge transfer \\
\hline $\begin{array}{l}\text { University of Wolverhampton } \\
\text { University of Hull }\end{array}$ & nFocus Limited & $\begin{array}{l}\text { Introduce an appropriate relationship marketing system, e-business applications and the development of sound sales } \\
\text { management/business development practices and activity. } \\
\text { Developing and implementing marketing strategies to expand existing markets and develop new business } \\
\text { opportunities. }\end{array}$ \\
$\begin{array}{l}\text { University of Strathclyde } \\
\text { University of Northampton }\end{array}$ & $\begin{array}{l}\text { SGB Services Limited } \\
\text { Green Label Foods } \\
\text { Limited }\end{array}$ & $\begin{array}{l}\text { Designing and implementing a business structure to improve and sustain the business performance. } \\
\end{array}$
\end{tabular}

Source: Based on KTP online archive filed under 'completed partnerships'.

The illustrations provided here need to be treated with caution. Asserting the definite presence of strategic clusters within the UK university system would necessitate a level of quantitative analysis of existing data to support, revise or reject our claims. The aim of providing the examples, as we have done in this paper, is to enhance understanding of the concreteness of the conceptual framework for knowledge production geared to the advancement of innovation activities, as discussed in the previous section. The principal idea suggested here is that there is an alternative way to conceptualising diversity of knowledge systems in university models. Strategic knowledge clusters can exist within a university system where there is little differentiation in governance structures and this diversity can be a key distinguishing feature with respect to its role in the wider national or regional innovation system.

\section{Evaluating Diversity in University Models}

There is evidence of diversity in university models in the UK, which manifests itself in distinctive knowledge clusters, as demonstrated in the previous section. The question, however, remains whether this multiplicity of university models is beneficial or detrimental to the innovation ecosystem. As has already been suggested, theories of innovation adopting a system perspective advocate, in most cases implicitly but in the case of THS quite explicitly, preference for one 'best' model of university. Paradoxically, this preference for one particular 
model of university in relation to the innovation ecosystem sits at odds with findings from a wide range of innovation studies. For instance, it is clear from Schumpeter's view (1934) that innovation is multi-dimensional: it can involve products, processes and organisational changes. While formal intellectual property can play a crucial role in developing 'new to the world' products, its impact in introducing and diffusing existing knowledge in a new context may be minimal. It is clear that universities can play vital roles in innovation processes that cover a broad landscape, as depicted in Table 2. As has been observed in the preceding section, multiple strategic clusters can exist within the university system and within each cluster are universities that specialise in the provision of similar kinds of innovation-related activities. The pursuit of one 'best' model can lead to a situation where policy makers would need to make judgements on the comparative value of different kinds of innovation. They have to answer questions like: which is more valuable - product, process, or organisational innovation? What is more relevant - 'new to world' or 'new to context' innovations? Specifically, they may have to make a choice between universities specialising in patents and licensing or universities developing more Knowledge Transfer Partnerships (KTPs). Such choices cannot be based on the theoretical and empirical findings of the innovation literature, which promotes heterogeneity of approaches and highlights the serendipitous nature of innovation processes (Rosenberg, 1994). From a theoretical point of view, therefore, there is a good rationale for maintaining diversity rather than focusing on similar specialisms across the sector. The examples presented give credence to this position.

A lack of diversity in a given university system can suggest two things: a) All universities within the system perform a narrow set of tasks. In India, as an example, universities are predominately examination-oriented and research is not considered to be a main function of academia (Datta, 2017). Homogeneity here is narrow in its scope. b) All universities within the system perform a broad range of similar tasks. In Britain, for example, notwithstanding the diversity that has been noted in the previous section, the university system has witnessed creeping mimetic institutional isomorphism (DiMaggio and Powell, 1983). Many new universities in the country which have traditionally specialised in tacit and practical knowledge (Table 5) processes have, over time, embraced explicit and theoretical knowledge production with equal vigour. Homogeneity here is broad in its scope.

Recent research on core competencies at the firm level firms however, lends support to the case for specialisation (Caspar and Whitley, 2004). Take, as an example, the case of the University of Oxford, which specialises in the production of codified knowledge and in its applications. The resources and capabilities of this University have been adapted to pursue this strategy effectively. This University has a low presence in the KTP area (it has only three KTP 
partnerships). This is anyway expected as the University's focus is on 'new to world' innovations, whereas KTPs essentially focus on 'new to context' applications.

So what can be said about the correlation between diversity in university models and innovation effort at regional and national levels? As has been shown through examples from the UK university sector, different innovation niches are served by various strategic clusters within academia engaged in the specialisation of different innovation-related activities. In line with scholars such as Trow (1997), Herbst (2004) and Carayannis et al., (2018b), this paper takes the position that on balance diversity is a good thing for the development of national and regional innovation systems but that it is important from the perspective of policy makers to ensure that the different models effectively cover the whole innovation landscape open to the knowledge sector. In other words, what is important is not diversity for its own sake but for its implication for the university sector, enabling it to realise its full potential within the national or regional innovation system. As in the UK, one also observes significant diversity in higher education models in the United States, a country where the university sector undoubtedly plays a central role in the national innovation system. Hollingsworth (2006: 426) describes the diversity as follows:

(I)n the United States, there have been small, elite, private universities such as Rockefeller University, the California Institute of Technology, and Rice University; there have been medium sized private universities, such as John Hopkins University, the University of Chicago, Vanderbilt University, Princeton, and there have been large private universities such as Harvard, Stanford and MIT, NYU. In addition, there are large public universities in California (Berkeley, UCLA, UCSD) and the Midwest (Michigan, Indiana, Wisconsin, Illinois, Minnesota). Each of these universities is a distinct type of population, somewhat differentiated from the other types of research organizations, in part because their dominant competencies are not easily learned or transmitted across organizational populations.

In the context of the UK, the distinction is not so much about universities being public or private as is the case in the United States, but about the specialised knowledge clusters within the sector which constitute 'distinct types of population' and are 'differentiated' from the other types on the basis of their distinctive competencies (Cooke and Huggins, 2018). It is also instructive to look at instances where the national innovation systems are considered sub-optimal and to investigate the extent of diversity in university models in those cases (Readman et al., 2018; Cunningham, et al., 2018). Empirical research in this area is sparse at the moment and indeed one way to extend this research in the future will be to conduct large scale surveys to investigate empirically the relationship between innovative capacity and diversity in university models and, on the back of this, to understand the direction of causality: does diversity in university models lead to higher innovative capacity or is the direction of causality the other way round? 
There is some anecdotal evidence to suggest that where national innovation systems are relatively under-developed there is often a lack of diversity within the university sector (Datta and Saad 2011). At this stage, however, any conclusion we draw about the impact of such diversity on national or regional innovation systems is tentative, at best.

\section{Conclusion}

This paper has challenged the monolithic conception of the university system within the frameworks of the NSI, THS and NIC and has shown, conceptually as well as with the help of specific illustrations, that there can be and indeed there is considerable diversity in university models in many countries, including the UK. The various contributions that the university sector make to the national innovation system have been highlighted and a conceptual framework has been presented that allows these activities to be mapped across two dimensions: the intensity of formal intellectual property associated with these activities and the proximity of the university to the culture and values of industry and the wider community. This paper has argued that diversity in university models emerges as different universities pursue specialisation in different innovation-related activities. This leads to the formation of strategic knowledge-based clusters within the sector. Within each cluster, universities specialise in similar kinds of innovation-related activities. Illustrations based on the university system in the UK have been used to demonstrate the presence of a few strategic clusters within the university sector. This paper suggests that, on balance, diversity in university models can be considered as an attractive feature of a nation's innovation system. This diversity, it has been argued, would enable universities to the exploit the different niches available within the innovation landscape effectively. It has been pointed out that the multidimensional nature of innovation requires different kinds of processes and it opens up opportunities to universities for specialisation. However, to make strong claims about the link between diversity in university models and enhancement of the innovative capacity of countries, a much larger survey would be required, involving cross-country studies focusing on the role of universities in innovation systems in each country. This paper has attempted to lay down the conceptual basis for such future work.

\section{References}


Acs, Z. J., Audretsch, D. B., Lehmann, E. E., and Licht, G. (2017). National systems of innovation. The Journal of Technology Transfer, 42(5), 997-1008.

Audretsch, D., Houweling, P. and Thurik, A.(2004) Industry evolution - Diversity, selection and the role of learning, International Small Business Journal, 22(4), 331-348.

Barney, J. (1991). Firm Resources and Sustained Competitive Advantage. Journal of Management, 17(1), 99-120.

Bush, V. (1945). Science The Endless Frontier: A Report to the President, Washington: United States Government Printing Office. Available at: http://www.nsf.gov/od/lpa/nsf50/vbush1945.htm.

Camagni, R. (ed.) (1991): Innovation Networks, (London, Belhaven)

Caruana, A., Ramaseshan, B. and Ewing, M. T. (1998). The Market Orientation-Performance Link: Some Evidence from the Public Sector and Universities, Journal of Nonprofit Sector Marketing, 6(1): 63-82.

Carayannis, E. G., Grigoroudis, E., Campbell, D. F., Meissner, D., \& Stamati, D. (2018a). The ecosystem as helix: an exploratory theory-building study of regional co-opetitive entrepreneurial ecosystems as Quadruple/Quintuple Helix Innovation Models. RED Management, 48(1), 148-162.

Carayannis, E. G., Grigoroudis, E., Campbell, D. F., Meissner, D., \& Stamati, D. (2018b). 'Mode 3'universities and academic firms: thinking beyond the box trans-disciplinarity and nonlinear innovation dynamics within coopetitive entrepreneurial ecosystems. International Journal of Technology Management, 77(1-3), 145-185.

Casper, S. and Whitley, R., 2004. Managing competences in entrepreneurial technology firms: a comparative institutional analysis of Germany, Sweden and the UK. Research Policy, 33(1), 89-106.

Coleman, J.S., (1988). Social capital in the creation of human capital. American Journal of Sociology (supplement) 94, S95-S120.

Conceição, P. and Heitor, M. V. (2005) Innovation for all?: learning from the Portuguese path to technical change and the dynamics of innovation. Westport, CT: Praeger.

Cooke, P., \& Huggins, R. (2018). High-technology clustering in Cambridge (UK). In The institutions of local development (pp. 63-84). Routledge.

Cunningham, J. A., Menter, M., \& O'Kane, C. (2018). Value creation in the quadruple helix: a micro level conceptual model of principal investigators as value creators. $R \mathcal{E} D$ Management, 48(1), 136-147

Danquah, M., \& Amankwah-Amoah, J. (2017). Assessing the relationships between human capital, innovation and technology adoption: Evidence from sub-Saharan Africa. Technological Forecasting and Social Change, 122, 24-33.

Datta, S. and Saad, M. (2011). University and Innovation Systems: The Case of India. Science and Public Policy, 38(1) 7-17. 
Dosi, G. (1982). Technological Paradigms and Technological Trajectories. Research Policy, 11, 147-162.

Dunn, M. B., and Jones, C. (2010). Institutional logics and institutional pluralism: The contestation of care and science logics in medical education, 1967-2005. Administrative Science Quarterly, 55: 114-149.

Edquist, C. (2005). 'Systems of Innovation: Perspectives and Challenges', in J. Fagerberg, D.C. Mowery and R.R. Nelson (Eds.), The Oxford Handbook of Innovation, Oxford: Oxford University Press.

Etzkowitz, H. and Dzisah, J. (2008). Rethinking development: Circulation in the triple helix. Technology Analysis \& Strategic Management, 20(6), 653-666.

Etzkowitz, H. and Leydesdorff, L. (2000) The dynamics of innovation: from National Systems and 'Mode 2' to a Triple Helix of university-industry-government relations. Research Policy, 29(2), 109-123.

Etzkowitz, H., Webster, A., Gebhardt, C. and Terra, B. (2000). The future of the university and the university of the future: evolution of ivory tower to entrepreneurial paradigm. Research policy, 29(2), 313-330.

Foray, D. (2004). The Economics of Knowledge. MIT Press, Cambridge MA.

Freeman, C. (2002) Continental, national andsub-national innovation systemscomplementarity and economic growth. Research Policy, 31(2), 191-211.

Freeman, C. (1995). The "National System of Innovation" in historical perspective. Cambridge Journal of Economics, 19(1), 5-24.

Furman, J.L., Porter, M.E. \& Stern, S. (2002). The determinants of national innovative capacity. Research Policy, 31 (6), 899-933.

Eastman, W. and Santoro, M. (2003) 'The importance of value diversity in corporate life', Business Ethics Quarterly, 13(4), 433-452.

Gibbons, M., Limogens, C., Nowotny, H., Schwartzman, S., Scott, P., and Trow, M. (1994). The New Production of Knowledge: The Dynamics of Science and Research in Contemporary Societies. Sage Publications: London.

Gimeno, J., Folta, T., Cooper, A., and Woo, C., (1997). Survival of the fittest? Entrepreneurial human capital and the persistence of underperforming firms. Administrative Science Quarterly 42 (4), 450-784.

Greenhalgh, C. and Rogers, M. (2010). Innovation, Intellectual Property, and Economic Growth, Princeton University Press: Princeton/Oxford.

Greve H. and Teh D. (2018) Goal selection internally and externally: A behavioural theory of institutionalization. International Journal of Management Reviews, 20: S19-38.

Grillitsch, M., Hansen, T., Coenen, L., Miörner, J., \& Moodysson, J. (2018). Innovation policy for system-wide transformation: The case of strategic innovation programmes (SIPs) 
in Sweden. Research Policy. https://doi.org/10.1016/j.respol.2018.10.004

Guena, A. (1999) The Economics of Knowledge Production. Edward Elgar, Cheltenham, UK.

Guena, A. and Muscio, A. (2009) The Governance of University Knowledge Transfer: A Critical Review of the Literature. Minerva, 47, 93-114.

Guena, A. and Nesta, L. (2006) University patenting and its effects on academic research: The emerging European evidence. Research Policy, 35, 790-807.

Guerrero, M., Cunningham, J. A., and Urbano, D. (2015). Economic impact of entrepreneurial universities' activities: An exploratory study of the United Kingdom. Research Policy, 44(3), 74

Gurin, P., Dey, E., Hurtado, S., and Gurin, G. (2002). Diversity and higher education: Theory and impact on educational outcomes. Harvard Educational Review, 72(3), 330-367.

Herbst, M. (2004). The production-morphology nexus of research universities: the Atlantic split. Higher Education Policy, 17(1), 5-21. 8-764.

Hicks, D. (2012). Performance-based university research funding systems, Research Policy 41(2), 251-261.

Hollingsworth, J.R., 2006. A Path Dependent Perspective on Institutional and Organizational Factors Shaping Major Scientific Discoveries. In J. Hage \& M. Meeus, eds. Innovation, Science, and Institutional Change: A Research Handbook: (Oxford University Press, Oxford/New York) 423-442.

Horta, H., Huisman, J. and Heitor, M., (2008) Does competitive research funding encourage diversity in higher education? Science and Public Policy, 35(3),146-158.

Ivanova, I.A. and Leydesdorff, L. (2014). Rotational symmetry and the transformation of innovation systems in a Triple Helix of university-industry-government relations. Technological Forecasting and Social Change, 86, 143-156.

Kline, S. \& Rosenberg, N. (1986). An Overview of Innovation. In R. Landau \& N. Rosenberg, eds. (National Academy Press, Washington DC).

Kwon, S., \& Motohashi, K. (2017). How institutional arrangements in the National Innovation System affect industrial competitiveness: A study of Japan and the US with multiagent simulation. Technological Forecasting and Social Change, 115, 221-235.

Leydesdorff, L. and Zawdie, G. (2010). The triple helix perspective on innovation system, Technology Analysis and Strategic management, 22(7), 789-804.

Liefner, I. (2003). Funding, resource allocation, and performance in higher education systems. Higher Education, 46, 469-489.

Lundvall, B. ed. (1992). National Systems of Innovation: Towards a Theory of Innovation and Interactive Learning, Pinter, London.

Malairaja, C. (2003). Learning from the Silicon Valley and implications for technological leapfrogging the experience of Malaysia. International Journal of Technology Management 
and Sustainable Development, 2(2),

Martin, B. (2003). The changing social contract for science and the evolution of university, in: Geuna, A., Salter, A.J., Steinmueller, W.E., (Eds), Science and innovation: rethinking the rationales for funding and governance. Edward Elgar, Cheltenham, UK.

Mowery, D.C. \& Sampat, B.N. (2005). Universities in National Innovation Systems. In J. Fagerberg, D. C. Mowery, \& R. R. Nelson, eds. The Oxford Handbook of Innovation, (Oxford University Press, Oxford) 209-239.

Nelson, R. \& Romer, P.M. (1996). Science, Economic Growth, and Public Policy. Challenge, March/April, 9-21.

Nelson, R.R. and Winter, S.G. (1982) An Evolutionary Theory of Economic Change. Harvard University Press.

Nelson, R. (1993). The National Innovation System: A Comparative Analysis, (Oxford University Press, New York).

Nonaka, Ikujiro, and H. Takeuchi. (1995). The Knowledge Creating Company: How Japanese Companies Create the Dynamics of Innovation. New York: Oxford University Press.

Pennings, J.M., Lee, K., van Witteloostuijn, A. (1998). Human capital, social capital, and firm dissolution. Academy of Management Journal 41 (4), 425-440.

Phillips, F. (2014). Triple helix and the circle of innovation. Journal of Contemporary East Asia, 13(1), 57-68.

Porter, M.E. (1979). The Structure within Industries and Companies' Performance. The Review of Economics and Statistics, 61(2), 214-227.

Porter, M. (1998). On Competition, (Harvard Business School Publishing, Boston).

Porter, M.E. \& Stern, S. (2002). National innovative capacity. In M. E. Porter et al., eds. (Oxford University Press, New York), pp.102-118.

Readman, J., Bessant, J., Neely, A., \& Twigg, D. (2018) Positioning UK research and technology organizations as outward-facing technology-bases. RED Management, 48(1), 109120.

Rosenberg, N. (1994). Exploring the black box: Technology, economics, and history, Cambridge University Press, Cambridge.

Saad, M., Zawdie, G. and Malairaja C. (2008) The triple helix strategy for universities in developing countries: the experiences in Malaysia and Algeria Science and Public Policy, 35(6): 431-443.

Saad, M., Guermat, C. and Brodie, L., (2015) National innovation and knowledge performance: The role of higher education teaching and training', The Journal of Higher Education Studies, 4, 7, 1194-1209.

Sanderson, M. (1972). The Universities and British Industry 1850-1970. Routledge \& Kegan Paul, London. 
Sarpong, D., AbdRazak, A., Alexander, E. and Meissner, D. (2017) Organizing practices of university, industry and government that facilitate (or impede) the transition to a hybrid triple helix model of innovation, Technological Forecasting and Social Change 123, 142-152.

Schumpeter, J. (1934). The Theory of Economic Development, Harvard University Press, Cambridge, Massachusset.

Scott, P., (1998). Shaking the ivory tower. The UNESCO Courier, Sept, 18-20.

Shane, S. (2004). Academic Entrepreneurship: University Spin-offs and Wealth Creation. Edward Elgar, Northampton, MA.

Short, J., Kitchen Jr, D., J., Palmer, T.B., and Hult, G. (2007) Firm, strategic group, and industry influences on performance. Strategic Management Journal 28, (2): 147-167.

Spender, J.C., (1996) Making knowledge the basis of a dynamic theory of the firm. Strategic Management Journal 17, (S2), 45-62.

Trow, M., (1997) ‘Reflections on diversity in higher education’ In M. Herbst, \& Latzel, G. and Lutz, L. (Eds.), Wandel im tertiaeren bildungssektor. zur position der schweiz im intemationalen vergleich (pp. 15-36). Zurich.

Valero, A., and Van Reenen, J. (2018). The economic impact of universities: Evidence from across the globe. Economics of Education Review. 68, 53-67.

Vallance, P., Blažek, J., Edwards, J., \& Květoň, V. (2018). Smart specialisation in regions with less-developed research and innovation systems: A changing role for universities? Environment and Planning C: Politics and Space, 36(2), 219-238.

Wheatley, M.J. (2001) Restoring hope to the future through critical education of leaders, Journal for Quality and Participation 24 (3), 46-49.

Wu, J., Zhuo, S., \& Wu, Z. (2017). National innovation system, social entrepreneurship, and rural economic growth in China. Technological Forecasting and Social Change, 121, 238250. 